\title{
COMPLEMENT SENSITIVITY AND FACTOR H BINDING OF EUROPEAN FRANCISELLA TULARENSIS SSP. HOLARCTICA STRAINS IN SELECTED ANIMAL SPECIES
}

\author{
Zsuzsa KreIZINGER $^{1 *}$, Mangesh BhIDE ${ }^{2}$, Elena BEnCUrova ${ }^{2}$, Saskia DolinsKA $^{2}$ \\ and Miklós GYURANECZ ${ }^{1}$ \\ ${ }^{1}$ Institute for Veterinary Medical Research, Centre for Agricultural Research, \\ Hungarian Academy of Sciences, Hungária krt. 21, 1143 Budapest, Hungary; \\ ${ }^{2}$ Department of Microbiology and Immunology, University of Veterinary Medicine \\ and Pharmacy, Košice, Slovakia
}

(Received 23 April 2015; accepted 22 June 2015)

\begin{abstract}
Francisella tularensis is a Gram-negative bacterium, the causative agent of the zoonotic disease tularaemia. The bacterium has developed several extracellular and intracellular strategies to evade the hosts' innate and adaptive immune responses. The aims of the study were to examine complement sensitivity of wild and attenuated $F$. tularensis ssp. holarctica strains in animal hosts of distinct sensitivity to the bacterium, to compare the complement-evading ability of wild strains of different phylogeographic background, and to examine the role of factor $\mathrm{H}$ in the host-pathogen interactions. Complement sensitivity assays were carried out on various $F$. tularensis ssp. holarctica wild strains and on the attenuated live vaccine strain (LVS) with sera of the highly sensitive house mouse (Mus muscu$l u s$ ), the moderately sensitive European brown hare (Lepus europaeus) and the relatively resistant cattle (Bos taurus). Specific binding of complement regulator factor $\mathrm{H}$ to bacterial membrane proteins was examined by Western blot assays. All wild strains interacted with the hosts' complement system and showed no significant differences in their survivability. The attenuated LVS was resistant to serum killing in mouse, but was lysed in the sera of hare and cattle. Direct binding of factor $\mathrm{H}$ to $F$. tularensis membrane proteins was not detected.
\end{abstract}

Key words: Cattle, evasion, factor $\mathrm{H}$, hare, mouse, tularaemia

Francisella tularensis is the aetiological agent of the zoonotic infection tularaemia. The Gram-negative, intracellular bacterium $F$. tularensis has worldwide distribution, occurring mainly in the northern hemisphere. In Europe the mildly virulent $F$. tularensis ssp. holarctica is endemic (Hestvik et al., 2014), and the strains of this subspecies are divided into two main phylogenetic groups, differing in their geographic distribution. In western European countries (France, Germany, Italy, the Netherlands, Spain, Switzerland) the B.FTNF002-00 group

*Corresponding author; E-mail: kreizinger.zsuzsa@agrar.mta.hu; Phone: 0036 (1) 467-4060; Fax: 0036 (1) 467-4076 
is dominant, while the B.13 group is most common in northern, central and eastern Europe (Austria, Czech Republic, Finland, Germany, Hungary, Romania, Russia, Slovakia, Sweden, Switzerland, Ukraine) (Vogler et al., 2009; Gyuranecz et al., 2012a; Antwerpen et al., 2013; Maraha et al., 2013; Ariza-Miguel et al., 2014; Origgi et al., 2014).

Francisella tularensis has a broad host spectrum, infecting mammals, birds and arthropods with most prominent occurrence in rodents and hares (Keim et al., 2007). The house mouse (Mus musculus) is extremely sensitive to tularaemia. It develops septicaemia and is killed shortly after infection, thus it generally does not seroconvert (Elkins et al., 2003; Chen et al., 2004). Even the attenuated live vaccine strain of $F$. tularensis ssp. holarctica (LVS) can produce lethal infection in mouse (Jones et al., 2012). The European brown hare (Lepus europaeus) is considered to be moderately sensitive to tularaemia. It seroconverts, develops subacute granulomatous lesions after infection and serves as a reservoir species for $F$. tularensis ssp. holarctica in central and eastern Europe (Gyuranecz et al., 2010; Gyuranecz et al., 2012b). Cattle (Bos taurus) are relatively resistant to tularaemia. When they are infected by $F$. tularensis, they seroconvert but do not develop clinical signs or lesions (Mörner and Sandstedt, 1983; Feldman, 2003).

For the successful invasion of the host system $F$. tularensis developed many mechanisms to evade extracellular and intracellular immune responses (Zarrella et al., 2011; Jones et al., 2012). The complement system is a major extracellular defence, part of the innate immune system, and it is activated by three pathways (classical, mannan-binding lectin and alternative pathways). All pathways lead to a cascade of signalling proteins resulting in lysis or opsonophagocytosis of the pathogen and the triggering of inflammatory responses. The three activation routes join in one key step, where the complement factor $\mathrm{C} 3$ is degraded by $\mathrm{C} 3$ convertase to its $\mathrm{C} 3 \mathrm{~b}$ and $\mathrm{C} 3 \mathrm{a}$ fragments, initiating the formation of the membrane attack complex (MAC) and inflammatory activities, respectively. The glycoprotein factor $\mathrm{H}(\mathrm{fH})$ is a member of the regulators of complement activity, which controls C3 convertase and serves as co-factor for factor I in the cleavage and inactivation of C3b (Janeway et al., 2001). As part of the subversion of the host's immunity many pathogens (e.g. Borrelia hermsii, Neisseria meningitidis, group A streptococci, Yersinia enterocolitica, Candida albicans) developed the ability to bind fH (Biedzka-Sarek et al., 2008; Meri et al., 2013), and interactions between $F$. tularensis and $\mathrm{fH}$ from human serum have also been described (Nasr and Klimpel, 2008).

The aims of this study were to compare the complement sensitivity of $F$. tularensis ssp. holarctica strains with different genetic background in the sera of three host species with distinct sensitivity to tularaemia (mouse, hare and cattle), and to discover whether the binding of $\mathrm{fH}$ could take part in the evasion of the immune system in animals as well. 


\section{Materials and methods}

Collection of $\mathrm{F}$. tularensis ssp. holarctica strains and sera

Three wild strains of $F$. tularensis ssp. holarctica originating from Italy, Spain and Hungary and the attenuated live vaccine strain originating from Russia (LVS, ATCC 29684) were used in the complement sensitivity and Western blot assays. Wild strains were isolated from natural infections of European brown hares and cultured on modified Francis agar (chocolate agar plate supplemented with $0.1 \%$ cysteine and $1 \%$ glucose). The genetic analysis of the strains was performed on the basis of RD23 (the region of genomic differences 23) deletion and single nucleotide polymorphism (SNP) typing as described before (Dempsey et al., 2007; Vogler et al., 2009). Based on their genetic characteristics the strains from Italy and Spain belong to the group B.FTNF002-00, while the strain from Hungary and LVS cluster in group B.13.

The sera of NMRI mice (Charles River Laboratories International, Inc., Wilmington, MA), European brown hares and cattle (Holstein-Friesian bread) were used to represent hosts that are highly or moderately (reservoir) sensitive or resistant to tularaemia, respectively. The sera were collected from healthy individuals (mouse, $\mathrm{n}=30$; hare, $\mathrm{n}=10$; cattle, $\mathrm{n}=10$ ) in accordance with all national and institutional regulations (permit number: 22.1/2703/003/2009). All sera were negative for antibodies against $F$. tularensis by slide and tube agglutination tests, using the commercially available Antigen Francisella tularensis (Bioveta, a.s., Ivanovice na Hané, Czech Republic). None of the animals were under antibiotic therapy during sampling, and sera were filtered through a $0.2 \mu \mathrm{m}$ filter (Minisart NML, Sartorius AG, Göttingen, Germany) before use.

\section{Complement sensitivity assay}

For the complement sensitivity assay $F$. tularensis ssp. holarctica strains were cultured in filtered $(0.2 \mu \mathrm{m}$ pore size, Minisart NML, Sartorius AG, Göttingen, Germany), modified brain-heart infusion (BHI) medium, containing $0.1 \%$ L-cysteine and 1\% D-glucose (Sigma-Aldrich Co. LLC, St. Louis, MO). An amount of $200 \mu \mathrm{l}$ of four-day-old bacterium culture of adjusted cell numbers (300 bacterial cells in $10 \mu \mathrm{l} \mathrm{BHI}$ ) was incubated together in 1:1 dilution with each serum at $37^{\circ} \mathrm{C}$ for $4 \mathrm{~h}$. Heat-inactivated sera $\left(30 \mathrm{~min}\right.$ at $\left.56^{\circ} \mathrm{C}\right)$ were used as inactive complement control. Each examination included a live cell control from the broth culture of the examined Francisella strains and a dead cell control from gentamicin- (100 $\mu \mathrm{g} / \mathrm{ml}$, Sigma-Aldrich Co. LLC., St. Louis, MO) killed bacteria from each strain. After incubation, cells were stained with propidium iodide (adding $1 \mu \mathrm{l}$ propidium iodide to $50 \mu \mathrm{l}$ broth culture and incubating for $8 \mathrm{~min}$ at room temperature with constant shaking) and examined by flow cytometry and fluorescent microscopy. The analyses were run on a FACS (Fluorescence- 
Activated Cell Sorting) single-laser flow cytometer (Becton, Dickinson and Company, Franklin Lakes, NJ). Events were counted in the list mode for one min, with $10 \mu 1 / \mathrm{min}$ sample fluid flow rate. Alive and dead cell controls were analysed first to construct the gates. For the discrimination and enumeration of alive and dead cells, gates were read on the logarithmically amplified FL-2 vs. FL-3 fluorescence dot plot. Data were analysed using the WinMDI software (Version 2.8). Examinations were carried out in triplicates on each sample and the mean values were used in the evaluations.

\section{Detection of complement regulator factor $H$ binding}

Western blots were carried out using the membrane proteins of the $F$. tularensis strains bound to nitrocellulose membrane. Bacterial cells in broth cultures were centrifuged $\left(15 \mathrm{~min}\right.$ at $5500 \mathrm{rpm}$ at $\left.4{ }^{\circ} \mathrm{C}\right)$, then treated with $1 \%$ protease inhibitor cocktail (ProteoBlock Protease Inhibitor Cocktail, Thermo Fisher Scientific Inc., Rockford, IL), and after sonication whole cell lysates were obtained from the supernatant of the centrifuged ( $30 \mathrm{~min}$ at $13,000 \mathrm{rpm}$ at $4{ }^{\circ} \mathrm{C}$ ) samples. Membrane proteins were gained from whole cell lysates using the Proteojet Membrane Protein Extraction kit (Thermo Fisher Scientific Inc., Rockford, IL) according to the manufacturer's instructions. Membrane proteins of each F. tularensis strain were run in polyacrylamide gels and transferred to nitrocellulose membranes $(0.45 \mu \mathrm{m}$ pore size, Thermo Fisher Scientific Inc., Rockford, IL) by electroblotting ( $2 \mathrm{~h}$ at $200 \mathrm{~V}$, XCell SureLock Electrophoresis Cell, Invitrogen, Carlsbad, CA). Bacterial membrane proteins were blocked in 2\% SMTTBS ( $2 \%$ skim milk in $0.05 \%$ Tween-20 Tris-Buffered Saline) for $1 \mathrm{~h}$, then incubated with the sera of different animal hosts (mouse, hare and cattle) for $2 \mathrm{~h}$ at room temperature. For the detection of possible interactions between membrane proteins and the complement regulator $\mathrm{fH}$, nitrocellulose membrane bound proteins were incubated for $1 \mathrm{~h}$ with polyclonal primary antibody of goat (concentration 1:200 in $0.5 \%$ SMTTBS; anti-factor H, Abcam PLC, Cambridge, UK) and for $1 \mathrm{~h}$ with rabbit anti-goat HRPO (concentration 1:50,000 in 0.5\% SMTTBS; Sigma-Aldrich Co. LLC., St. Louis, MO) secondary antibody. After a final step of 5-min incubation with SuperSignal West Pico Chemiluminescent Substrate (Thermo Scientific Pierce Protein Research Products, Rockford, IL), the chemiluminescence of the samples was measured with a blot scanner (LI-COR C-DiGit, LI-COR Biotechnology, Lincoln, NE). Membrane proteins of B. hermsii were incubated together with serum of mouse and the antibodies described above for use as positive control (Bhide et al., 2009). Borrelia hermsii binds fH with its $20 \mathrm{kDa}$ protein, FhbA. 


\section{Statistics}

Independent $t$-test was performed to evaluate differences in the results of complement sensitivity assays. The absolute values of the differences between mean values of number of events in normal and inactivated sera in the case of wild and attenuated $F$. tularensis spp. holarctica strains, and in groups B.FTNF002-00 and B.13 within the wild strains were compared in each host species.

\section{Results and discussion}

As an intracellular bacterium $F$. tularensis has to evade a diverse spectrum of extracellular and intracellular defence reactions during its pathogenesis. Moreover, for its rapid dissemination in the host system, the bacterium survives and replicates extracellularly in the blood system; thus the subversion of a firstline defence system, the complement system is crucial in the bacterial invasion (Yu et al., 2008; Clinton et al., 2010).

The complement sensitivity assays performed in the present study on three wild and one attenuated $F$. tularensis ssp. holarctica strains showed differences in the resistance of the strains to serum killing and among the hosts' susceptibility (Fig. 1), in conformity with previous observations (Jones et al., 2012).

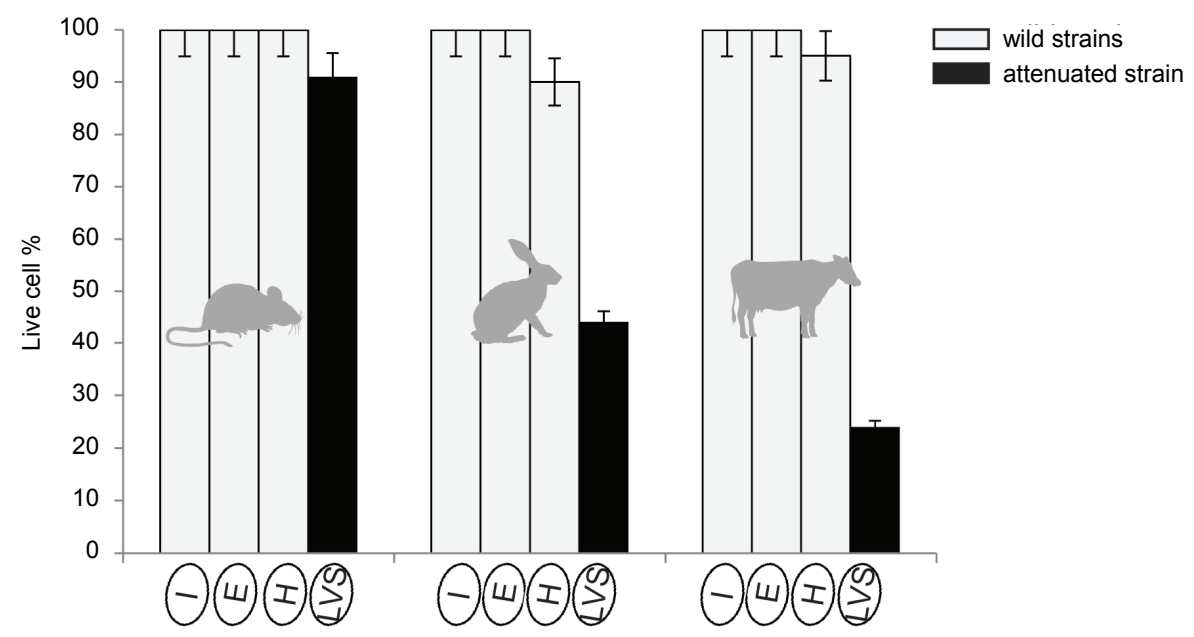

Fig. 1. Percentage of live Francisella tularensis ssp. holarctica bacterial cells in the sera of house mouse (Mus musculus), brown hare (Lepus europaeus) and cattle (Bos taurus) in complement sensitivity assays. Values represent the percentage of live bacterial cells in normal sera compared to live cell numbers in heat-inactivated sera after incubation at $37^{\circ} \mathrm{C}$ for $4 \mathrm{~h}$, determined by flow cytometry. Animal icons (mouse, hare and cattle) represent the origin of the sera examined. Abbreviations represent $F$. tularensis ssp. holarctica strains: strain 21851 from Italy, B.FTNF002-00 group (I), strain Ft6 from Spain, B.FTNF002-00 group (E), strain TUL32 from Hungary, B.13 group $(\mathrm{H})$ and live vaccine strain (ATCC 29684), B.13 group (LVS) 
In tularaemia and intracellular bacteria research, a frequently used experimental infection model is the mouse infected with $F$. tularensis ssp. holarctica LVS, as the strain has attenuated virulence in humans, but still can cause lethal disease in mice (Elkins et al., 2003). In the current study, the complement sensitivity assays showed that most bacterial cells stayed intact after incubation with mouse serum in every case examined by flow cytometry (Fig. 1) and fluorescent microscopy as well. The demonstrated resistance of the attenuated LVS strain to serum killing in mouse is consistent with the known high susceptibility of this animal species to tularaemia (Elkins et al., 2003).

The European brown hare, a main source of human infections, is considered to be a reservoir species for F. tularensis ssp. holarctica B.13 strains in central and eastern Europe, developing subacute pathological changes during infection (Gyuranecz et al., 2010; Gyuranecz et al., 2012a; Gyuranecz et al., 2012b). In the current study, flow cytometric analyses showed a decreased number of events in the LVS broth culture after incubation with normal hare serum compared to cultures incubated with heat-inactivated hare serum (Fig. 1). Examinations by fluorescent microscope confirmed bacterial cell lysis in the assays with normal hare serum and LVS (data not shown). In contrast with the attenuated strain, the wild strains (both B.FTNF002-00 and B.13 isolates) stayed intact after incubation with normal hare serum, which is in accordance with the virulence characteristics of the strains.

Francisella tularensis is probably transmitted to cattle by blood-sucking arthropod vectors, and seroconversion of cattle was reported several times during the past decades, but clinical signs due to tularaemia have not been described in this species (Mörner and Sandstedt, 1983; Feldman, 2003). The relative resistance of cattle to $F$. tularensis suggests a limited role of this host in the epidemiology of the pathogen (Mörner and Sandstedt, 1983). In the present study, a noticeable elevation of fluorescence emission and a significant decrease in the number of live cell events $(\mathrm{P}=0.003)$ were observed in LVS broth culture after incubation with normal cattle serum compared to incubation with inactivated cattle serum due to mass bacterial cell killing. However, no significant differences were detected in the dead and alive cell rates between wild bacterial strains (B.FTNF002-00 and B.13 isolates) incubated with normal or inactivated cattle serum.

The differences in virulence among $F$. tularensis subspecies or even among genetic clades of subspecies are noticeable, e.g. in the case of the highly virulent $F$. tularensis ssp. tularensis clade A1 and clade A2, which latter may have similar virulence to the mildly virulent $F$. tularensis ssp. holarctica (Keim et al., 2007; Molins et al., 2010). In the present study, the comparison of the genetically and geographically distinct $F$. tularensis ssp. holarctica wild strains, originating from Italy and Spain (B.FTNF002-00 genetic group) and from Hungary (B.13 genetic group) revealed no relevant differences in their survivability in the serum of the animal species examined. 
Previously, the binding of $\mathrm{fH}$ complement regulator protein to the surface of both $F$. tularensis ssp. tularensis strain SchuS4 and F. tularensis ssp. holarctica strain LVS has been described in humans (Nasr and Klimpel, 2008). However, the exact mechanism of this binding has not been discovered yet, but fibrinogen and/or plasmin are hypothesised to have a promoter role in $\mathrm{fH}$ binding to F. tularensis cell surface (Crane et al., 2009; Jones et al., 2012). Although in the present study host-pathogen interactions were observed by complement sensitivity assays, further examinations on $\mathrm{fH}$ binding to bacterial cell membrane proteins using Western blot assays did not reveal specific interactions in any of the animal species examined (Fig. 2). The lack of direct fH binding to F. tularensis membrane proteins might result from the absence of a co-factor (e.g. fibrinogen or plasmin) or may represent a difference in the individual hosts' immunity and might suggest that the pathogen does not use fH binding during complement evasion in animal hosts.

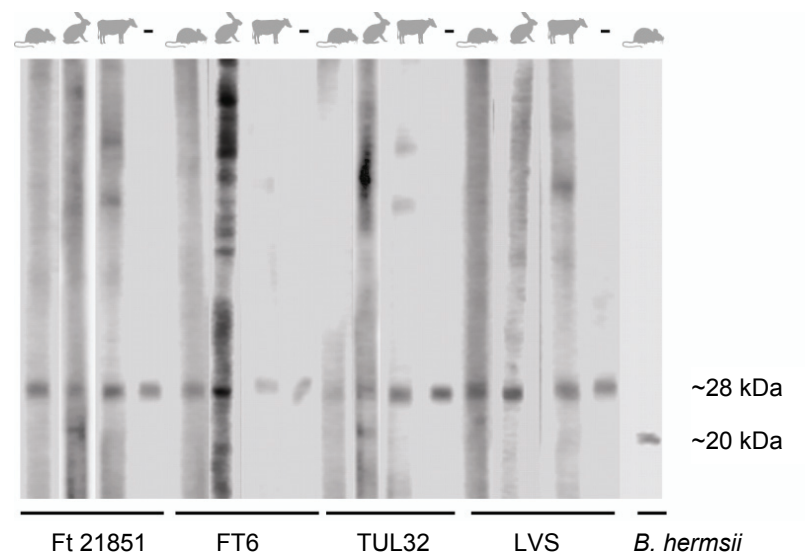

Fig. 2. Western blot assays for the detection of factor $\mathrm{H}(\mathrm{fH})$ binding with Francisella tularensis ssp. holarctica strains in selected animal species. Animal icons (mouse, hare and cattle) represent the origin of the sera examined; negative control (-) excluding sera from the reagents are presented in each case. Abbreviations represent the positive control Borrelia hermsii (B. hermsii) and F. tularensis ssp. holarctica strains: strain Ft 21851 from Italy, B.FTNF002-00 group, strain FT6 from Spain, B.FTNF002-00 group, strain TUL32 from Hungary, B.13 group and live vaccine strain (ATCC 29684), B.13 group (LVS). Borrelia hermsii binds fH with its $20 \mathrm{kDa}$ protein, FhbA. Non-specific binding of primary antibody by $\sim 28 \mathrm{kDa}$ Francisella membrane protein can be observed

In conclusion, complement sensitivity assays on four $F$. tularensis ssp. holarctica strains of different genetic and geographic character and on three animal species with different sensitivity to tularaemia showed interactions between host and pathogen in all but two cases. While bacterial cells of the three wild strains survived in the sera of mouse, hare and cattle as well, the attenuated bacterial cells could evade only the mouse complement system and were killed by both hare and cattle sera. Despite the genetic and geographic alterations among 
the wild strains no relevant differences were detected in their ability to resist serum killing, which highlights the importance of clarifying the reasons for the phylogeographic distribution of this pathogen. As opposed to observations in humans, the binding of complement regulator factor $\mathrm{H}$ to $F$. tularensis surface proteins in the examined animal species was not detected, supposedly for the lack of an intermediate component or because of interspecies differences.

\section{Acknowledgements}

This study was funded by the Lendület (Momentum) programme (LP2012-22) of the Hungarian Academy of Sciences, the SAIA (66801) National Scholarship Programme of the Slovak Republic, APVV-0036/10 grant, VEGA-1/0054/12 grant and structural funds for centres of excellence-26220120002 (INFEKTZOON). EB is funded by ITMS 26220220185 . Funders did not have any involvement in the conduction of the study. Wild strains of $F$. tularensis ssp. holarctica from Spain and Italy were kindly provided by Pedro Anda and Massimo Fabbi, respectively.

\section{References}

Antwerpen, M. H., Schacht, E., Kaysser, P. and Splettstoesser, W. D. (2013): Complete genome sequence of a Francisella tularensis subsp. holarctica strain from Germany causing lethal infection in common marmosets. Genome Announc. 1, e00135-12. doi:10.1128/genomeA. 00135-12.

Ariza-Miguel, J., Johansson, A., Fernández-Natal, M. I., Martínez-Nistal, C., Orduña, A., Rodríguez-Ferri, E. F., Hernández, M. and Rodríguez-Lázaro, D. (2014): Molecular investigation of tularemia outbreaks, Spain, 1997-2008. Emerg. Infect. Dis. 20, 754. doi: http://dx.doi.org/10.3201/eid2005.130654.

Bhide, M. R., Escudero, R., Camafeita, E., Gil, H., Jado, I. and Anda, P. (2009): Complement factor $\mathrm{H}$ binding by different Lyme disease and relapsing fever Borrelia in animals and human. BMC Res. Notes 2, 134. doi:10.1186/1756-0500-2-134.

Biedzka-Sarek, M., Jarva, H., Hyytiäinen, H., Meri, S. and Skurnik, M. (2008): Characterization of complement factor H binding to Yersinia enterocolitica serotype O: 3. Infect. Immun. 76, $4100-4109$.

Chen, W., KuoLee, R., Shen, H. and Conlan, J. W. (2004): Susceptibility of immunodeficient mice to aerosol and systemic infection with virulent strains of Francisella tularensis. Microb. Pathog. 36, 211-218.

Clinton, S. R., Bina, J. E., Hatch, T. P., Whitt, M. A. and Miller, M. A. (2010): Binding and activation of host plasminogen on the surface of Francisella tularensis. BMC Microbiol. 10, 76. doi:http://www.biomedcentral.com/1471-2180/10/76.

Crane, D. D., Warner, S. L. and Bosio, C. M. (2009): A novel role for plasmin-mediated degradation of opsonizing antibody in the evasion of host immunity by virulent, but not attenuated, Francisella tularensis. J. Immunol. 183, 4593-4600.

Dempsey, M. P., Dobson, M., Zhang, C., Zhang, M., Lion, C., Gutiérrez-Martín, C. B., Iwen, P. C., Fey, P. D., Olson, M. E., Niemeyer, D., Francesconi, S., Crawford, R., Stanley, M., Rhodes, J., Wagner, D. M., Vogler, A. J., Birdsell, D., Keim, P., Johansson, A., Hinrichs, S. H. and Benson, A. K. (2007): Genomic deletion marking an emerging subclone of Francisella 
tularensis subsp. holarctica in France and the Iberian Peninsula. Appl. Environ. Microbiol. 73, 7465-7470.

Elkins, K. L., Cowley, S. C. and Bosio, C. M. (2003): Innate and adaptive immune responses to an intracellular bacterium, Francisella tularensis live vaccine strain. Microbes Infect. 5, 135-142.

Feldman, K. A. (2003): Tularemia. JAVMA-J. Am. Vet. Med. A 222, 725-730.

Gyuranecz, M., Birdsell, D. N., Splettstoesser, W., Seibold, E., Beckstrom-Sternberg, S. M., Makrai, L., Fodor, L., Fabbi, M., Vicari, N., Johansson, A., Busch, J. D., Vogler, A. J., Keim, P. and Wagner, D. M. (2012a): Phylogeography of Francisella tularensis subsp. holarctica, Europe. Emerg. Infect. Dis. 18, 290-293.

Gyuranecz, M., Reiczigel, J., Krisztalovics, K., Monse, L., Szabóné, G. K., Szilágyi, A., Szépe, B., Makrai, L., Magyar, T., Bhide, M. and Erdélyi, K. (2012b): Factors influencing emergence of tularemia, Hungary, 1984-2010. Emerg. Infect. Dis. 18, 1379-1380.

Gyuranecz, M., Szeredi, L., Makrai, L., Fodor, L., Mészáros, Á. R., Szépe, B., Füleki, M. and Erdélyi, K. (2010): Tularemia of European brown hare (Lepus europaeus) A pathological, histopathological, and immunohistochemical study. Vet. Pathol. 47, 958-963.

Hestvik, G., Warns-Petit, E., Smith, L. A., Fox, N. J., Uhlhorn, H., Artois, M., Hannant, D., Hutchings, M. R., Mattsson, R., Yon, L. and Gavier-Widen, D. (2014): The status of tularemia in Europe in a one-health context: a review. Epidemiol. Infect. 30, 1-24.

Janeway, C. A. Jr., Travers, P., Walport, M. and Shlomchik, M. J. (2001): The complement system and innate immunity. In: Immunobiology: The Immune System in Health and Disease. 5th edition. Garland Science, New York. Available from: http://www.ncbi.nlm.nih.gov/ books/NBK27100/

Jones, C. L., Napier, B. A., Sampson, T. R., Llewellyn, A. C., Schroeder, M. R. and Weiss, D. S. (2012): Subversion of host recognition and defense systems by Francisella spp. Microbiol. Mol. Biol. Rev. 76, 383-404.

Keim, P., Johansson, A. and Wagner, D. M. (2007): Molecular epidemiology, evolution, and ecology of Francisella. Ann. N. Y. Acad. Sci. 1105, 30-66.

Maraha, B., Hajer, G., Sjödin, A., Forsman, M., Paauw, A., Roeselers, G., Verspui, E., Frenay, I., Notermans, D., de Vries, M. and Reubsaet, F. (2013): Indigenous infection with Francisella tularensis holarctica in the Netherlands. Case Rep. Infect. Dis. Article ID 916985. doi: http://dx.doi.org/10.1155/2013/916985.

Meri, T., Amdahl, H., Lehtinen, M. J., Hyvärinen, S., McDowell, J. V., Bhattacharjee, A., Meri, S., Marconi, R., Goldman, A. and Jokiranta, T. S. (2013): Microbes bind complement inhibitor factor H via a common site. PLoS Pathog. 9, e1003308. doi:10.1371/journal.ppat.1003308.

Molins, C. R., Delorey, M. J., Yockey, B. M., Young, J. W., Sheldon, S. W., Reese, S. M., Schriefer, M. E. and Petersen, J. M. (2010): Virulence differences among Francisella tularensis subsp. tularensis clades in mice. PLoS One 5, e10205. doi: 10.1371/journal. pone. 0010205 .

Mörner, T. and Sandstedt, K. (1983): A serological survey of antibodies against Francisella tularensis in some Swedish mammals. Nord. Vet. Med. 35, 82-85.

Nasr, A. B. and Klimpel, G. R. (2008): Subversion of complement activation at the bacterial surface promotes serum resistance and opsonophagocytosis of Francisella tularensis. J. Leukocyte Biol. 84, 77-85.

Origgi, F., Frey, J. and Pilo, P. (2014): Characterisation of a new group of Francisella tularensis subsp. holarctica in Switzerland with altered antimicrobial susceptibilities, 1996 to 2013. Euro. Surveill. 19, pii=20858. Available online: http://www.eurosurveillance.org/View Article.aspx?ArticleId $=20858$.

Vogler, A. J., Birdsell, D., Price, L. B., Bowers, J. R., Beckstrom-Sternberg, S. M., Auerbach, R. K., Beckstrom-Sternberg, J. S., Johansson, A., Clare, A., Buchhagen, J. L., Petersen, J. M., Pearson, T., Vaissaire, J., Dempsey, M. P., Foxall, P., Engelthaler, D. M., Wagner, D. M. and Keim, P. (2009): Phylogeography of Francisella tularensis: global expansion of a highly fit clone. J. Bacteriol. 191, 2474-2484. 
Yu, J. J., Raulie, E. K., Murthy, A. K., Guentzel, M. N., Klose, K. E. and Arulanandam, B. P. (2008): The presence of infectious extracellular Francisella tularensis subsp. novicida in murine plasma after pulmonary challenge. Eur. J. Clin. Microbiol. 27, 323-325.

Zarrella, T. M., Singh, A., Bitsaktsis, C., Rahman, T., Sahay, B., Feustel, P. J., Gosselin, E. J., Sellati, T. J. and Hazlett, K. R. O. (2011): Host-adaptation of Francisella tularensis alters the bacterium's surface-carbohydrates to hinder effectors of innate and adaptive immunity. PLoS One 6, e22335. doi:10.1371/journal.pone.0022335. 